\title{
AVALIAÇÃO DA EFICIÊNCIA DO REATOR UASB TRATANDO EFLUENTE DE LATICÍNIO SOB DIFERENTES CARGAS ORGÂNICAS
}

\author{
The efficiency of UASB reactor treating dairy effluent at diferent organic loading rates
}

\author{
Cláudio Milton Montenegro Campos ${ }^{1}$, Fátima Aparecida Resende de Luiz ${ }^{2}$, \\ Cláudio Gouvêa Botelho ${ }^{3}$, Leonardo Henrique Soares Damasceno ${ }^{4}$
}

\begin{abstract}
RESUMO
Avaliou-se o desempenho de um reator anaeróbio de manta de lodo (UASB) em escala laboratorial quanto à eficiência na remoção da carga poluidora, utilizando como substrato leite tipo B, diluído com concentração média de 2.500 mg. $\mathrm{L}^{-1}$, similar aos efluentes de laticínios quando descartado o soro. Durante os 205 dias de operação, o reator foi avaliado em relação à eficiência, de acordo com a carga orgânica volumétrica (COV) aplicada. O incremento da COV aplicada foi realizado com a redução do tempo de detenção hidráulica; com isso, os TDH(s) médios aplicados no reator foram de 12, 20, 18 e 16 horas. A carga orgânica biológica (COB) inicial, ou seja, de partida, foi de 0,054 kgDBO.kgSVT ${ }^{-1}$.dia ${ }^{-1}$. O reator apresentou eficiências de 24, 43, 52 e $39 \%$, na remoção de $\mathrm{DQO}_{\mathrm{T}}$, e 22, 22, 17 e 17\% na remoção de sólidos totais para os respectivos TDH(s) aplicados. Os melhores resultados do reator UASB na remoção de matéria orgânica foram obtidos com os TDH (s) de 20 e 18 horas. Nas condições de temperatura, carga orgânica volumétrica (COV) e tempo de detenção hidráulica (TDH) aplicados, o reator demonstrou boas condições de tamponamento, sendo desnecessária a correção do pH, o que significa minimização de custos.
\end{abstract}

Termos para indexação: Laticínios, reator UASB, sistemas de tratamento, tratamento anaeróbio.

\begin{abstract}
In this research it was evaluated the performance of a laboratory scale UASB reactor (Upflow Anaerobic Sludge Blanket) treating a simulated dairy wastewater. In order to obtain the same concentration of an ordinary dairy, in terms of COD substrate, it was carried out the dilution of type B pasteurized milk with drinking water at a mean concentration of 2,500 mg. $\mathrm{L}^{-1}$, similar to a dairy wastewater without milk serum. During 205 days of operation the reactor was evaluated considering the efficiency related to the organic loading rate, which varied according to the hydraulic detention time applied. The UASB reactor was operated at different hydraulic retention times, of about 12, 20, 18 and 16 hours. The initial (start-up) biological organic loading rate was about $0,054 \mathrm{~kg}$ DBO. $\mathrm{kg} \mathrm{TVS}^{-1} \cdot \mathrm{d}^{-1}$. The observed removal efficiencies of organic matter in terms of COD (Chemical Oxygen Demand), were about 24, 43, 52 and 39\%, whereas, the removal of TS (total solids) were about 22, 22, 17 and $17 \%$, concerning to the respectively application of hydraulic detention times. The best results related to the removal of organic matter were obtained with the hydraulic retention time (HRT) of 20 and 18 hours. Under the applied temperature, the volumetric loading rate and hydraulic retention time, the reactor demonstrated good condition of buffering and efficiency.
\end{abstract}

Index terms: Dairy, UASB reactor, treatment systems, anaerobic treatment.

(Recebido para publicação em 16 de dezembro de 2002 e aprovado em 24 de novembro de 2004)

\section{INTRODUÇÃO}

Minas Gerais é o maior produtor de leite do Brasil, com mais de 5 bilhões de litros/ano, o que equivale a $30 \%$ de toda produção nacional (MINAS AMBIENTE, 1998). Isso faz com que o Estado seja caracterizado pela sua enorme indústria de laticínios, um importante segmento alimentício.

O processo de beneficiamento do leite gera um volume de efluentes líquidos no mínimo três vezes maior, dos quais mais de $90 \%$ desse montante não recebe qualquer tipo de tratamento, SEBRAE/MG $(1997,1998)$. Isso se deve ao fato de a maioria dos laticínios ser de pequeno e médio porte, com dificuldades financeiras para manter pessoal especializado, capaz de trabalhar com inovações tecnológicas e operar sistemas de tratamento de efluentes. Com o objetivo de se racionalizar o uso de energia e recursos naturais e também de proteger o meio ambiente, desenvolvendo uma produção sustentável, foi escolhido o processo biológico anaeróbio.

A biodegradação anaeróbia depende de uma população microbiana diversificada e estável. Esses microrganismos sintetizam a matéria orgânica, transformando-a em metano e dióxido de carbono, Braile, 1993. A eficiência

\footnotetext{
1. Professor Adjunto II, Ph.D, Departamento de Engenharia da Universidade Federal de Lavras/UFLA - Caixa Postal 3037 - $37200-000$ - Lavras, MG.cmmcampos@ufla.br

2. Bolsista/CNPq - Departamento de Engenharia/UFLA. fatima.luiz@uol.com.br

3. Professor Adjunto IV, M.Sc, Departamento de Engenharia/UFLA. claubote@ufla.br

4. Engenheiro Agrícola, Departamento de Engenharia/UFLA. Ihsd@dr.com
} 
do processo depende das interações entre as diversas espécies bacterianas e ainda das condições específicas de operação, como temperatura, $\mathrm{pH}$ e tipo de substrato, entre outros.

Dos fatores físicos que afetam a atividade microbiana, a temperatura é dos mais importantes na seleção das espécies, pois pode afetar a velocidade do metabolismo das bactérias, o equilíbrio iônico e a solubilidade dos substratos. De acordo com Chernicharo (1997), a produção de metano pode ocorrer em uma faixa bastante ampla de temperatura, de 0 a $97^{\circ} \mathrm{C}$, sendo dois os níveis de temperatura ótima: faixa mesofílica, 30 a $35^{\circ} \mathrm{C}$ (bactérias mesofílicas) e a faixa termofílica, 50 a $55^{\circ} \mathrm{C}$ (bactérias termofílicas). Deve-se optar por temperaturas que, em termos de custo benefício, dêem melhor resultado.

Quanto ao $\mathrm{pH}$, a produção de metano pelas bactérias se dá na faixa de 6,8 a 7,4, e valores abaixo de 6,0 podem inibir por completo a geração de metano. As bactérias produtoras de ácidos voláteis têm um crescimento ótimo na faixa de 5 a 6 , tendo uma tolerância maior em valores mais baixos de pH (CAMPOS, 1998). A interação entre a alcalinidade e a acidez fundamentase na capacidade de tamponamento do sistema, ou seja, a de neutralizar os ácidos formados no processo.

Segundo Campos et al. (2000), o processo anaeróbio de tratamento minimiza os custos de implantação e manutenção, obtendo-se como subproduto energético o gás metano, e um dos sistemas de tratamento utilizados é o reator UASB (Upflow Anaerobic Sludge Blanket).

O sistema exige uma pequena demanda de área de instalação e é capaz de apresentar eficiência satisfatória em termos de remoção de Demanda Bioquímica de Oxigênio (DBO). Portanto, sua implantação torna-se uma boa alternativa para países em desenvolvimento, tais como o Brasil.

No presente trabalho, teve-se por objetivo avaliar o desempenho de um reator anaeróbio de manta de lodo (UASB), constituído em escala laboratorial, na remoção da carga orgânica de efluentes líquidos da agroindústria de laticínios, sob diferentes tempos de detenção hidráulica.

\section{MATERIAL E MÉTODOS}

O experimento foi conduzido no Laboratório de Análises de Águas do Departamento de Engenharia (LAADEG) da Universidade Federal de Lavras (UFLA). As unidades de tratamento foram operadas durante 205 dias (agosto de 2001 a março de 2002), divididas em quatro fases em função dos TDH(s) aplicados.

\section{Unidades experimentais}

O sistema de tratamento foi constituído de três unidades: tanque de acidificação e equalização
(TAE), tanque de flotação-aeração (FLOT) e reator UASB, com os seguintes volumes: 55; 13 e 11,7 litros, respectivamente. O TAE foi adaptado a um contêiner fabricado em polipropileno (PP), objetivando acidificar e hidrolisar os compostos afluentes. $\mathrm{O}$ FLOT utilizado na remoção de óleos e graxas funcionava com ar comprimido distribuído por meio de mangueiras perfuradas, as quais ficavam fixadas na sua parte inferior do referido tanque. A relação entre o volume do FLOT e as demais unidades foi elevada, com o propósito de incrementar a eficiência da referida unidade.

O reator UASB foi construído em vidro, sendo em seu interior instalado um separador de três fases de formato piramidal. O nível de biogás dentro do separador de três fases (gás-sólido-líquido) foi mantido utilizando um equalizador de pressão. Ao longo do perfil do reator, foram instalados amostradores para coleta e análise do lodo. A representação esquemática do sistema é apresentada na Figura 1.

\section{Partida do sistema "Start-up"}

Para a partida do reator, foi utilizado como inóculo lodo digerido anaerobiamente, proveniente da mistura do lodo do próprio sistema em estudo, o qual já se encontrava em funcionamento anteriormente, com o lodo adquirido de uma estação de tratamento da CCPL. O reator foi inoculado com 6 litros de lodo, o que correspondia aproximadamente a $52 \%$ do seu volume útil. O lodo de partida apresentou teor de sólidos voláteis totais (SVT) de $26.887 \mathrm{mg} . \mathrm{L}^{-1}$.

\section{Monitoramento do sistema}

O efluente utilizado para alimentação do sistema foi obtido pela diluição de leite pasteurizado tipo B (da marca Ipê) com água potável, a fim de se obter uma DQO de $2.500 \mathrm{mg} . \mathrm{L}^{-1}$. A adoção desse valor justifica-se por corresponder aos valores comumente encontrados em efluentes líquidos das indústrias de laticínios que não lançam soro em seus efluentes (SEBRAE/MG, 1998). O leite diluído também possui características de óleos e graxas e caseína normalmente superiores aos efluentes de laticínios convencionais.

A alimentação do sistema foi realizada em bateladas no TAE e, posteriormente, o efluente, após passar por um sistema de aquecimento serpentinado, era bombeado para o FLOT, e, em seguida, introduzido no reator UASB. Na Figura 2 está apresentado o fluxograma das unidades experimentais. 


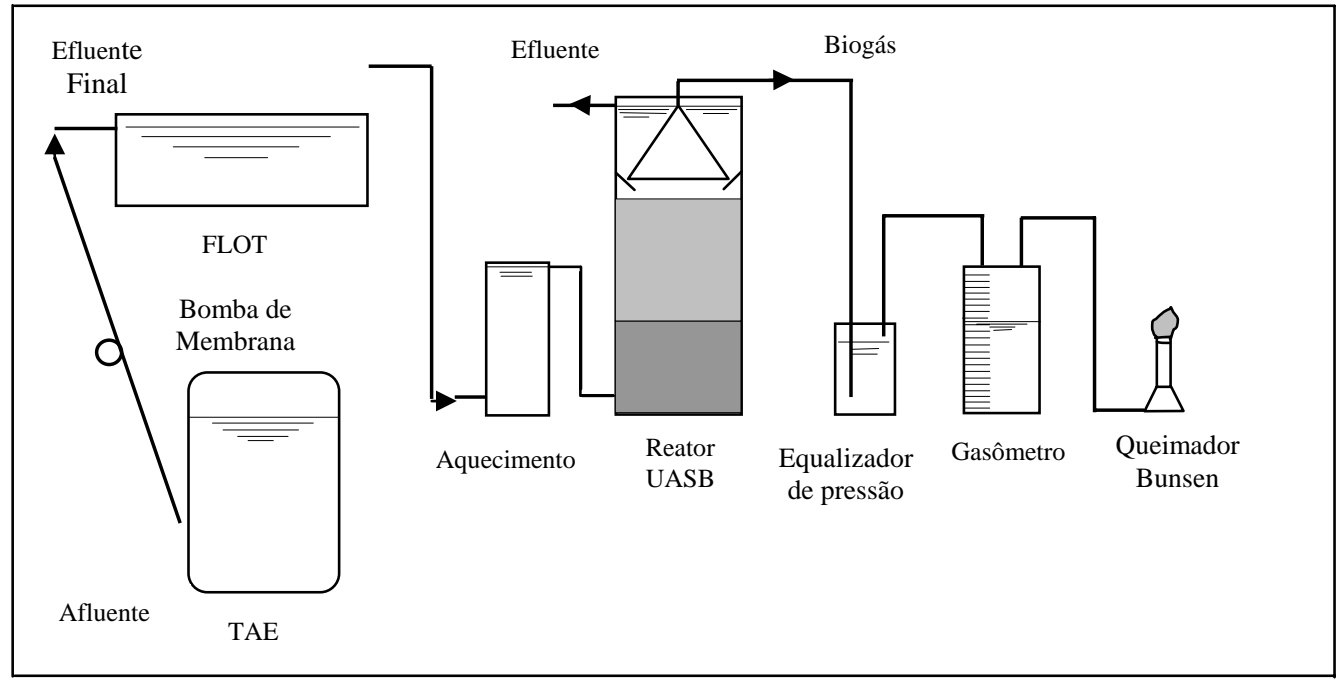

FIGURA 1 - Representação esquemática do sistema proposto.

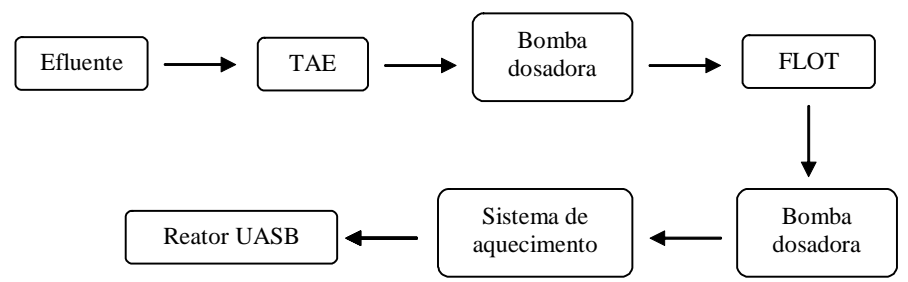

FIGURA 2 - Fluxograma das unidades experimentais

Durante as recargas do sistema, tomou-se o cuidado de homogeneizar o efluente, deixando-o em repouso de 10 a 15 minutos antes de fazer a coleta, a fim de que houvesse maior representatividade. A recarga era realizada toda vez que o volume de efluente restante no TAE correspondia a $20 \%$ do seu volume útil. O controle da vazão da bomba foi feito, volumetricamente, utilizando-se um frasco de volume (erlenmeheyer). As determinações de temperatura, $\mathrm{pH}$, vazão, alcalinidade e acidez total foram realizadas diariamente, enquanto as análises de $\mathrm{DQO}_{\mathrm{T}}, \mathrm{ST}$, SFT e SVT foram realizadas sempre que se fazia a recarga no TAE. As amostras foram analisadas de acordo com Standard... (1998).

\section{RESULTADOS E DISCUSSÃO}

\section{Condições de operação}

Os seguintes $\mathrm{TDH}(\mathrm{s})$ foram testados: 12, 20, 18 e 16 horas. Inicialmente, o reator UASB foi monitorado com TDH de 12 horas e carga orgânica biológica (COB) de 0,054 kgDBO.kgSVT ${ }^{-1} \cdot$ dia $^{-1}$, a fim de se obter, posteriormente, redução do TDH, aumentando-se, gradativamente, a COB em função da estabilidade do sistema. Durante aproximadamente 25 dias, o TDH foi mantido igual a 12 horas; porém, conforme podese verificar na Tabela 1, logo após ocorreu aumento do TDH para 20 horas. Isso aconteceu devido à grande perda de sólidos (lodo) do reator.

TABELA 1 - Parâmetros de operação.

\begin{tabular}{lcccc}
\hline \multirow{2}{*}{ Parâmetros (médios) } & \multicolumn{4}{c}{ TDH(s) Adotados } \\
\cline { 2 - 5 } & $\begin{array}{c}\mathbf{1 2} \\
\text { horas }\end{array}$ & $\begin{array}{c}\mathbf{2 0} \\
\text { horas }\end{array}$ & $\begin{array}{c}\mathbf{1 8} \\
\text { horas }\end{array}$ & $\begin{array}{c}\mathbf{1 6} \\
\text { horas }\end{array}$ \\
\hline Duração (dias) & 25 & 55 & 58 & 66 \\
Vazão $\left(\mathrm{L} \cdot \mathrm{h}^{-1}\right)$ & 1 & 0,6 & 0,64 & 0,72 \\
CHV $\left(\mathrm{m}^{-3} \cdot \mathrm{m}^{-3} \cdot \mathrm{d}^{-1}\right)$ & 1,89 & 1,13 & 1,2 & 1,37 \\
COV $\left(\mathrm{kgDQO} \cdot \mathrm{m}^{-3} \cdot \mathrm{d}^{-1}\right)$ & 1,57 & 0,34 & 0,41 & 0,71 \\
COB $\left(\mathrm{kgDBO} \cdot \mathrm{kgSVT}^{-1} \cdot \mathrm{d}^{-1}\right)$ & 0,054 & 0,02 & 0,042 & 0,101 \\
\hline
\end{tabular}


A vazão foi estipulada de acordo com o TDH desejado, havendo pequena variação devido à alta precisão da bomba. Essa pequena variação pode ser explicada pelo acúmulo de sólidos nas tubulações, e a diminuição da vazão, causando seu entupimento. Na Tabela 1 estão mostrados os valores de vazão para os respectivos TDH(s) aplicados.

Para despejos solúveis industriais ou domésticos, o valor da CHV no reator não pode ul- trapassar $5 \mathrm{~m}^{3} \cdot \mathrm{m}^{-3} \cdot \mathrm{dia}^{-1}$, o que não procede no sistema em questão"(CAMPOS, 1998). Valores superiores ao citado poderiam prejudicar o funcionamento do sistema, causando perda excessiva de biomassa, diminuição do grau de estabilização de sólidos e possível falha do sistema, pois o tempo de permanência da biomassa pode ser inferior ao seu crescimento.

TABELA 2 - Valores médios dos parâmetros monitorados.

\begin{tabular}{|c|c|c|c|c|c|}
\hline \multirow{2}{*}{ Parâmetros } & & \multicolumn{4}{|c|}{ Valores Médios } \\
\hline & & 12horas & 20 horas & 18 horas & 16 horas \\
\hline Temperatura & UASB & 26 & 26 & 26 & 26 \\
\hline \multirow{2}{*}{$\mathrm{pH}$} & Afluente & 6,04 & 7,00 & 6,86 & 6,95 \\
\hline & Efluente & 6,37 & 7,21 & 7,16 & 7,27 \\
\hline \multirow{2}{*}{ Alcalinidade (mg.L ${ }^{-1}$ ) } & Afluente & - & 49 & 59 & 70 \\
\hline & Efluente & - & 69 & 67 & 85 \\
\hline \multirow{2}{*}{ Acidez (mg.L ${ }^{-1}$ ) } & Afluente & - & 9 & 20 & 22 \\
\hline & Efluente & - & 11 & 12 & 18 \\
\hline \multirow{2}{*}{$\mathrm{DQO}_{\mathrm{T}}\left(\mathrm{mg} \cdot \mathrm{L}^{-1}\right)$} & Afluente & 797 & 288 & 312 & 473 \\
\hline & Efluente & 582 & 147 & 138 & 286 \\
\hline \multirow{2}{*}{$\mathrm{ST}\left(\mathrm{mg} \cdot \mathrm{L}^{-1}\right)$} & Afluente & 545 & 268 & 298 & 411 \\
\hline & Efluente & 426 & 212 & 239 & 339 \\
\hline \multirow{2}{*}{ SFT (mg.L $\left.L^{-1}\right)$} & Afluente & 119 & 74 & 78 & 101 \\
\hline & Efluente & 118 & 77 & 64 & 101 \\
\hline \multirow{2}{*}{ SVT (mg.L $\left.{ }^{-1}\right)$} & Afluente & 426 & 200 & 220 & 311 \\
\hline & Efluente & 307 & 135 & 175 & 238 \\
\hline
\end{tabular}

TABELA 3 - Eficiência média dos parâmetros monitorados.

\begin{tabular}{lcccc}
\hline \multirow{2}{*}{ Parâmetros } & \multicolumn{5}{c}{ Eficiência (\%) } \\
\cline { 2 - 5 } & $\mathbf{1 2}$ horas & $\mathbf{2 0}$ horas & $\mathbf{1 8}$ horas & $\mathbf{1 6}$ horas \\
\hline DQO $_{\mathrm{T}}\left(\mathrm{mg} . \mathrm{L}^{-1}\right)$ & 24 & 43 & 52 & 39 \\
\hline $\mathrm{ST}\left(\mathrm{mg} . \mathrm{L}^{-1}\right)$ & 22 & 22 & 17 & 17 \\
\hline SVT $\left(\mathrm{mg} . \mathrm{L}^{-1}\right)$ & 27 & 32 & 15 & 22 \\
\hline SFT $\left(\mathrm{mg} . \mathrm{L}^{-1}\right)$ & -4 & -2 & 19 & -6 \\
\hline
\end{tabular}


Com relação à temperatura, pode ser visto na Figura 3 que ocorreram variações causadas pela variação da temperatura dentro do laboratório onde o experimento foi conduzido. Para os quatros TDH(s) adotados, o reator trabalhou com temperatura média de $26^{\circ} \mathrm{C}$ (Tabela 2). A fim de garantir essa temperatura no reator, o sistema de aquecimento trabalhou com temperatura média de $36^{\circ} \mathrm{C}$. A temperatura média ambiente foi de $23^{\circ} \mathrm{C}$. Com isso, o reator UASB operou na faixa mesofílica (entre 25 e $40^{\circ} \mathrm{C}$ ). Com o objetivo de minimizar a energia necessária para manter a temperatura do processo, as tubulações foram revestidas com material isolante.

\section{pH, alcalinidade e acidez}

Os valores referentes ao $\mathrm{pH}$, alcalinidade e acidez estão apresentados na Tabela 2. Observa-se na Figura 4 que, exceto durante a fase com TDH de 12 horas, o reator apresentou valores dentro da faixa em que as bactérias metanogênicas têm um bom desempenho $(\mathrm{pH}$ entre 6 e pH 8). Segundo Fulford (1988), a formação de ácido orgânico no início do processo pode reduzir o pH; com isso, as bactérias metanogênicas começam a transformar os ácidos em produtos gasosos e o $\mathrm{pH}$ retorna a um nível próximo do neutro.

A pequena variação no $\mathrm{pH}$ demonstrou a boa capacidade de tamponamento do sistema, a qual pode ser definida como a capacidade de uma solução em evitar mudanças bruscas no $\mathrm{pH}$.

Para o TDH de 12 horas, não foram feitas análises de alcalinidade e acidez. Relacionando o $\mathrm{pH}$ com alcalinidade e acidez, notou-se que quando o $\mathrm{pH}$ afluente do reator apresentava valores inferiores ao efluente, ocorria a alcalinidade, caso contrário, ocorria a acidez. Para sistemas anaeróbios com pH entre 6,0 e 7,5, a capacidade de tamponamento é quase que completamente dependente dos bicarbonatos, os quais em equilíbrio com a dissociação do ácido carbônico (proveniente do dióxido de carbono), tendem a regular a concentração do íon hidrogênio, como a seguir:

$$
\begin{aligned}
\mathrm{CO}_{2}+\mathrm{H}_{2} \mathrm{O} & \longrightarrow \mathrm{HCO}_{3}^{-}+\mathrm{H}^{+} \\
\mathrm{HCO}_{3}{ }^{-}+\mathrm{OH}^{-} & \longrightarrow \mathrm{CO}_{3}{ }^{2-}+\mathrm{H}_{2} \mathrm{O}
\end{aligned}
$$

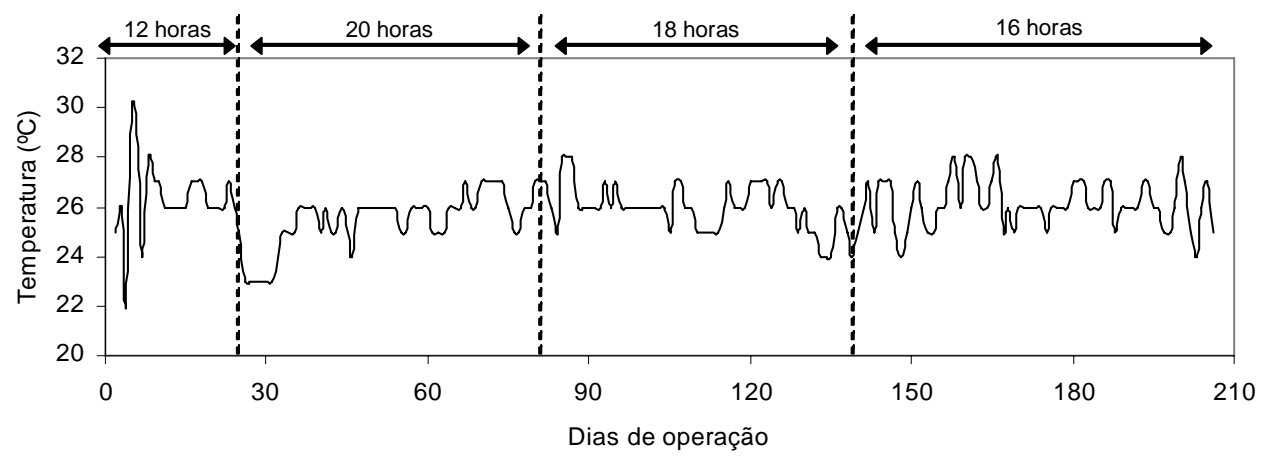

FIGURA 3 - Variação da temperatura no UASB.

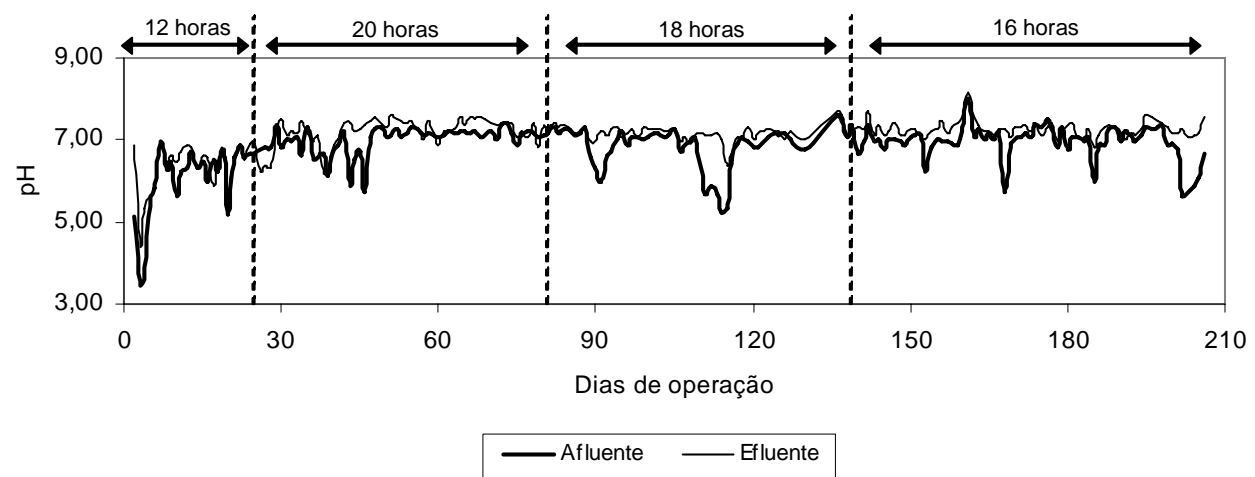

FIGURA 4 - Variação do pH no UASB. 
Isso significa que a diminuição do $\mathrm{pH}$ implicará uma maior liberação de íons de hidrogênio, que, reagindo com $\mathrm{HCO}_{3}{ }^{-}$, diminuirão a alcalinidade do meio. A elevação do $\mathrm{pH}$ causa aumento da alcalinidade pela formação do $\mathrm{CO}_{3}{ }^{2-}$. As variações da alcalinidade e da acidez estão apresentadas na Figuras 5 e 6.

\section{Demanda Química de Oxigênio (DQO)}

Analisando-se a Figura 7a, observa-se que ocorreram grandes variações na $\mathrm{DQO}_{\mathrm{T}}$ afluente para os quatros TDH (s) adotados. Essa variação ocorreu em razão da pouca precisão na diluição do leite em água potável. Os valores de $\mathrm{DQO}_{\mathrm{T}}$ apresentados foram influenciados pela presença de sólidos nas amostras.

Para o TDH de 12 horas, ocorreram valores negativos na remoção de $\mathrm{DQO}_{\mathrm{T}}$ no UASB. Isso pode ser explicado pela ocorrência de uma possível sobrecarga de óleos e graxas no reator, o que ocasionou a adsorção de gordura no lodo bacteriano, provocando um arraste de sólidos e interferindo na remoção de $\mathrm{DQO}_{\mathrm{T}}$. Assim, houve um aumento do TDH e, conseqüentemente, redução da COB (Tabela 1). Após a alteração do TDH para 20 horas, a eficiência média na remoção de DQO passou de $24 \%$ para $43 \%$. Esse TDH foi mantido por um período de 55 dias, até que o reator demonstrasse certa estabilidade na remoção de $\mathrm{DQO}_{\mathrm{T}}$. Logo após, o TDH no reator foi reduzido para 18 horas, obtendo-se, nessa fase, eficiência média na remoção de DQO de 52\%. Com a redução do TDH de 20 para 18 horas, ocorreu um aumento da carga hidráulica volumétrica de 1,13 para $1,2 \mathrm{~m}^{3} \cdot \mathrm{m}^{-3} \cdot$ dia ${ }^{-1}$, a qual promoveu a "saída" do lodo volumoso, com características pobres de sedimentabilidade e permitiu o desenvolvimento de um lodo granular de alta atividade, que provocou aumento da eficiência na remoção de DQO no UASB. Entretanto, a remoção de DQO começou a decrescer com a redução do TDH de 18 para 16 horas. Durante todo esse período, o reator apresentou baixos valores de eficiência. Essa queda pode ser explicada pela sobrecarga de óleos e graxas. Esses compostos, com certeza, aderem-se aos sólidos, diminuindo a densidade deles e, conseqüentemente, permitindo o arraste do lodo bacteriano, prejudicando a eficiência dessa unidade. As eficiências na remoção de DQO para os quatro TDH(s) adotados podem ser visualizadas na Tabela 3.

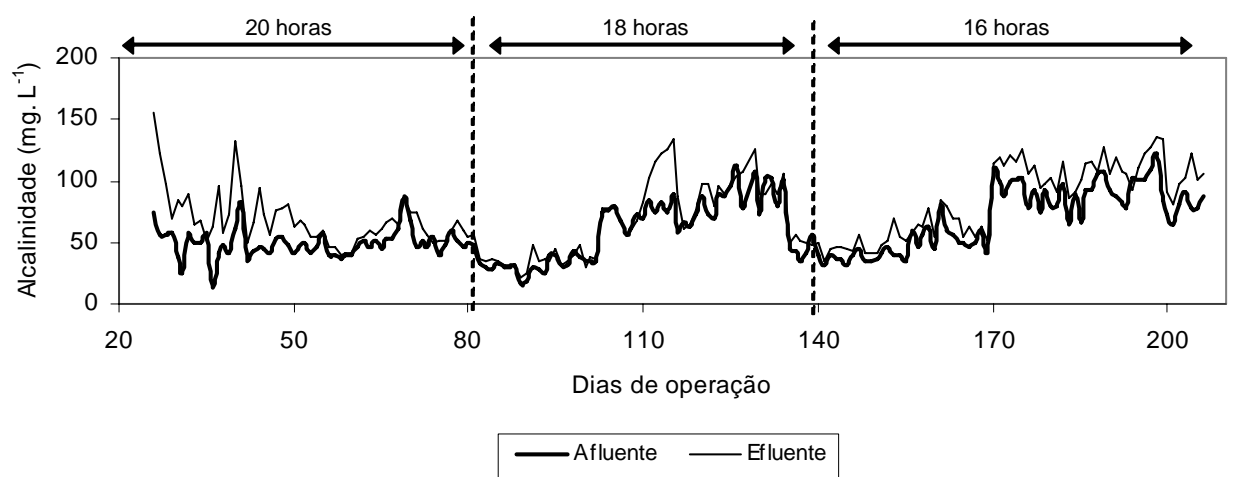

FIGURA 5 - Variação da alcalinidade no UASB

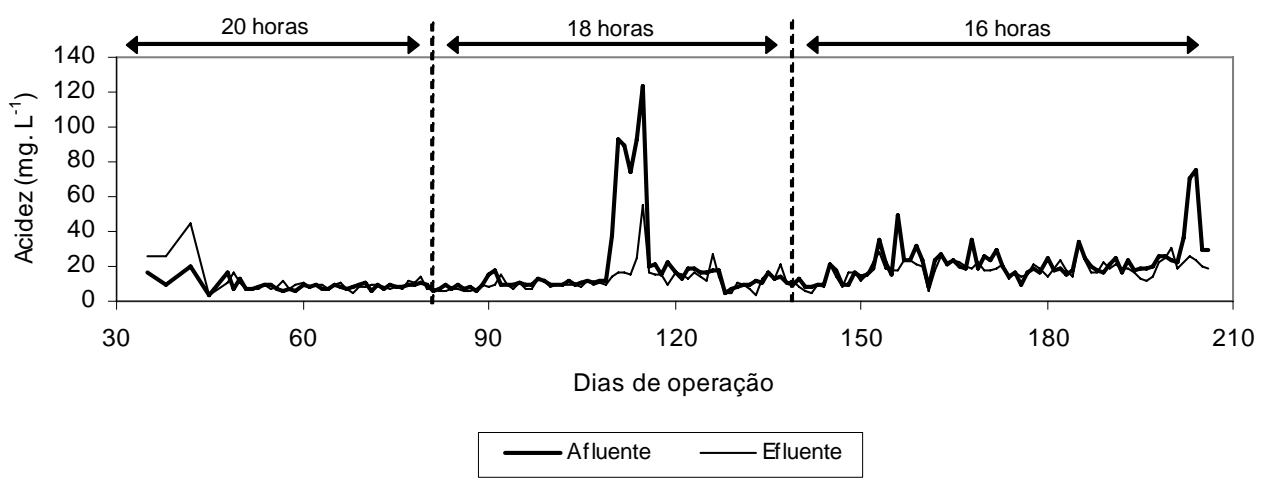

FIGURA 6 - Variação da acidez no UASB. 
Verifica-se na Tabela 1 que o reator não foi submetido a elevadas $\operatorname{COV}(\mathrm{s})$, o que prejudicaria o desenvolvimento da biomassa bacteriana. Na Figura 9 está mostrada a variação da COV em função do TDH aplicado no reator UASB. Comparando as $\operatorname{COV}(\mathrm{s})$ médias com as eficiências do UASB, observa-se que o aumento da COV para 0,41 $\mathrm{KgDQO} \cdot \mathrm{m}^{-3} \cdot \mathrm{d}^{-1}$ promoveu um incremento na eficiência do UASB, demonstrando boa aclimatização do lodo a esse tipo de substrato e permitindo, assim, o cultivo de um lodo de boa qualidade (esse cultivo é lento e corresponde a uma etapa importantíssima no processo).

Di Bernardo et al. (1991) avaliaram em escala piloto um reator anaeróbio de manta de lodo no tratamento de efluentes líquidos provenientes de laticínios. A carga orgânica biológica (COB) adotada para partida foi de 0,2 KgDQO.KgSSV ${ }^{-1} \cdot \mathrm{d}^{-1}$, obtendo eficiência na remoção de DQO de $60 \%$ para $\mathrm{CHV}$ de $0,67 \mathrm{~m}^{3} \cdot \mathrm{m}^{-3} \cdot \mathrm{d}^{-1}$ (TDH igual a 36 horas). Após a alteração da CHV para $1 \mathrm{~m}^{3} \cdot \mathrm{m}^{-3} \cdot \mathrm{d}^{-1}$ (TDH igual a 24 ho- ras) , houve um período de adaptação com a redução da remoção de DQO; porém, após um período de 2 semanas, a eficiência retornou ao valor anterior - no final do experimento, a remoção de DQO alcançou 83\%, considerando amostra não filtrada e 86\% para amostra filtrada.

\section{Sólidos Totais (ST), Sólidos Fixos Totais (SFT) e Sólidos Voláteis Totais (SVT)}

Na Tabela 2 verifica-se a variação do teor dos diferentes tipos sólidos no afluente e efluente do reator.

A quantidade elevada de sólidos no efluente, principalmente para os TDH(s) de 12 e 16 horas, decorreu do carreamento de lodo do reator, resultante talvez da carga hidráulica aplicada ou mesmo da produção de biogás, cujo movimento ascensional das bolhas provocava perda de sólidos.

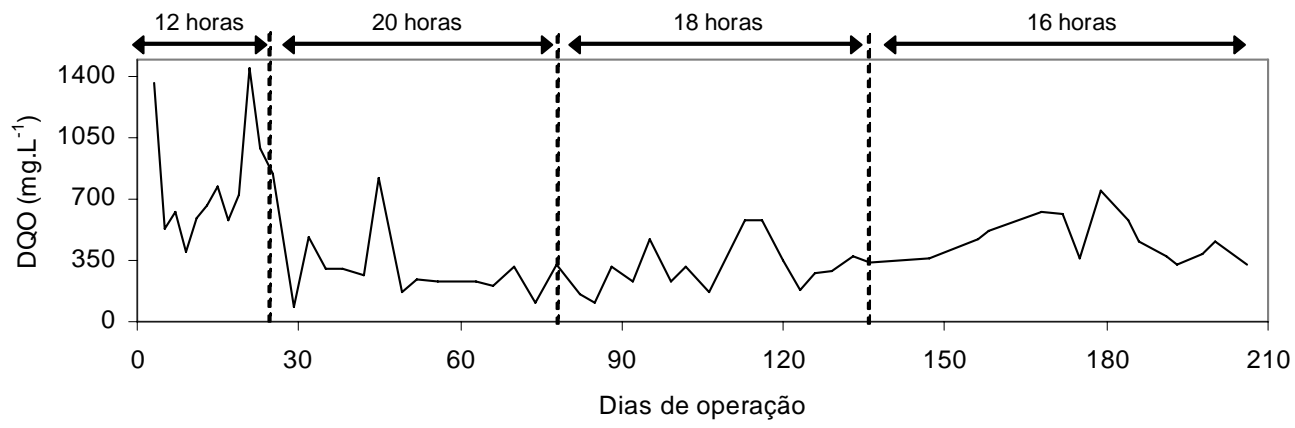

FIGURA 7a - Variação da DQO afluente do UASB.

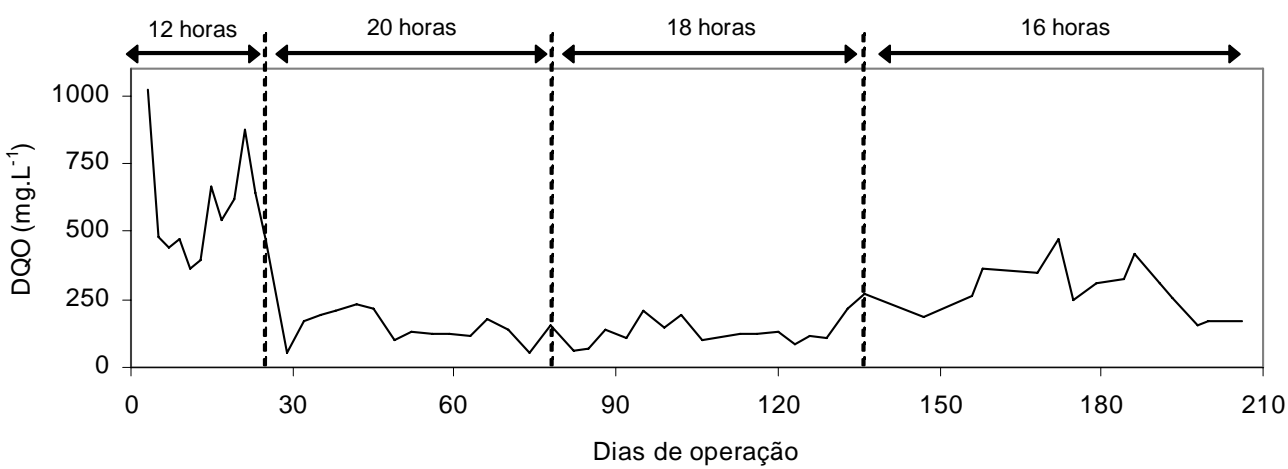

FIGURA 7b - Variação da DQO efluente do UASB. 
A eficiência na remoção de sólidos voláteis totais foi devida a materiais de fácil biodegradação, tais como proteínas, açúcares, lipídios, etc, presentes no efluente. Assim, nota-se que a maior parte do afluente do reator era constituído de material de fácil degradação devido aos altos valores de SVT em relação aos SFT. Na Figura 10 verifica-se a variação de ST afluente e efluente ao reator para cada TDH adotado. A eficiência na remo- ção de sólidos voláteis quase sempre foi positiva, o que não ocorreu com os sólidos fixos totais. Segundo Leite (1997), para resíduos com percentuais maiores de sólidos voláteis totais, haverá maior acréscimo na taxa de produção de gás $\mathrm{CH}_{4}$, tornando essa alternativa de tratamento mais viável economicamente. As eficiências na remoção de ST, SFT e SVT podem ser visualizadas na Tabela 3.

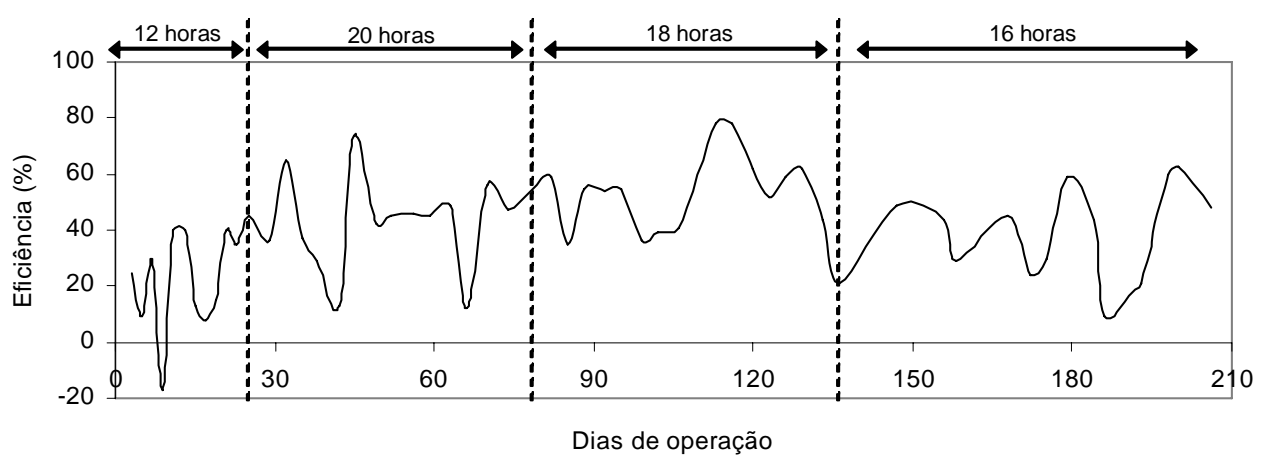

FIGURA 8 - Variação da eficiência na remoção de DQO no UASB.

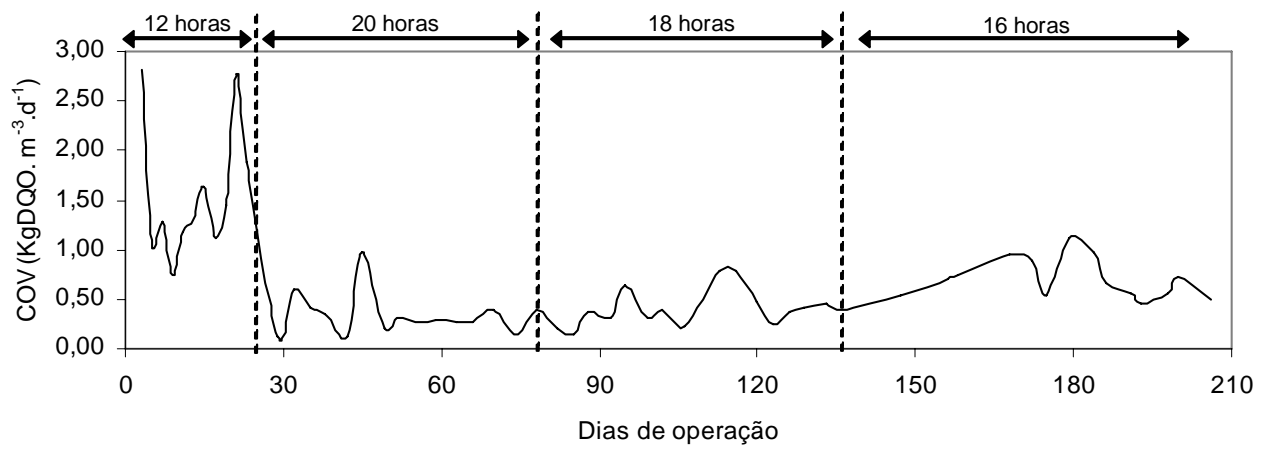

FIGURA 9 - Variação da COV no UASB.

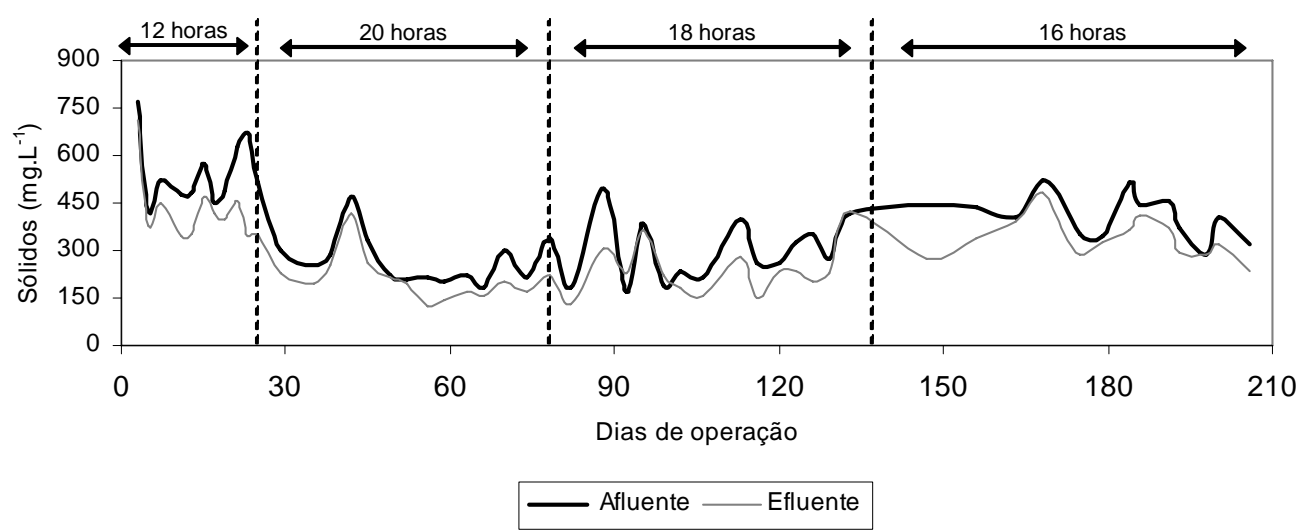

FIGURA 10 - Variação de ST no reator UASB. 


\section{CONCLUSÕES}

Pelos resultados obtidos durante o período de monitoramento, pode-se chegar às seguintes conclusões:

a) O reator UASB apresentou, neste caso específico, eficiências relativamente baixas; no entanto, por se tratar de efluente com alto teor de óleos e graxas, os referidos valores de remoção podem ser considerados bons, tendo de antemão conhecimento de que outras unidades (polimento) deverão ser instaladas para atender aos padrões de lançamento.

b) O sistema apresentou boas condições de tamponamento, sendo desnecessária a correção do $\mathrm{pH}$, o que significa minimização de custos.

c) Em virtude da verificação da presença de partículas em suspensão nas amostras de efluentes provenientes do reator, deve-se realizar as referidas análises com amostras filtradas.

d) Em função dos parâmetros adotados, o TDH de 18 horas foi o que apresentou melhor eficiência durante o tratamento, podendo esse parâmetro ser considerado como valor ideal na otimização do sistema.

\section{AGRADECIMENTOS}

Ao Departamento de Engenharia da Universidade Federal de Lavras (DEG/UFLA), pelo uso de suas dependências físicas, e ao Conselho Nacional de Desenvolvimento Científico e Tecnológico - CNPq, pela concessão de bolsas PIBIC.

O projeto foi desenvolvido no âmbito do convênio celebrado entre a UFLA e a empresa de base tecnológica Global Ciência e Tecnologia - GCT.

\section{REFERÊNCIAS BIBLIOGRÁFICAS}

CAMPOS, C. M. M. Reatores anaeróbios de última geração. Lavras: UFLA, 1998. 59 p. Apostila.
CAMPOS, C. M. M. et al. Partida de um sistema anaeróbio em escala piloto constando de um tanque de contato seguido de um reator UASB tratando efluente de laticínio. In: OFICINA E SEMINÁRIO LATINOAMERICANO DE DIGESTÃO ANAERÓBIA, 6., 2000, Recife. Anais... Recife: [s.n.], 2000. v. 2, p. 6164.

CHERNICHARO, C. A. L. Reatores anaeróbios. Belo Horizonte: DESA/UFMG, 1997. 246 p.

DI BERNARDO, L. et al. Emprego de reator anaeróbio de fluxo ascendente com manto de lodo para tratamento de despejos líquidos provenientes de laticínios. Revista Dae, São Paulo, v. 51, n. 161, p. 19-24, jul./ago. 1991.

FULFORD, D. Running a biogás program: a handbook. London: Intermediate Technology, 1988. 187 p.

LEITE, V. D. Processo de tratamento anaeróbio de resíduos sólidos urbanos inoculados com lodo de esgoto industrial. 1997. 250 f. Tese (Doutorado) - Universidade de São Paulo, São Carlos, 1997.

MINAS AMBIENTE. Introdução laticínios. Belo Horizonte, 1998. Disponível em: <http://urano.cdtn.br/ mg-amb/laticin.htm>. Acesso em: 08 mar. 2001.

SEBRAE/MG. Diagnóstico da indústria de laticínios do Estado de Minas Gerais. Belo Horizonte, 1997. 270 p.

SEBRAE/MG. Pesquisa tecnológica para controle ambiental em pequenos e médios laticínios de Minas Gerais. Belo Horizonte, 1998. v. 1.

STANDARD methods for the examination of water and wastewater. 20. ed. New York: American Public Health Association, 1998. 